\title{
Aging and situation model processing
}

\author{
GABRIEL A. RADVANSKY \\ University of Notre Dame, Notre Dame, Indiana \\ AND \\ KATINKA DiJKSTRA \\ Florida State University, Tallahassee, Florida
}

\begin{abstract}
Over the past several years, a number of studies have been done that assess processing at the level of the situation model in relation to issues of aging (Morrow, Leirer, \& Altieri, 1992; Radvansky, Copeland, Berish, \& Dijkstra, 2003; Radvansky, Copeland, \& Zwaan, 2003; Stine-Morrow, Gagne, Morrow, \& DeWall, 2004; Stine-Morrow, Morrow, \& Leno, 2002). In contrast to age-related declines that have been demonstrated at surface form and textbase levels of processing, no such declines have been found in the creation and updating of situation models (Radvansky, 1999). This review focuses on the relevant factors in cognitive aging and situation model processing and places them within the larger frameworks of language processing, working memory capacity, and aging.
\end{abstract}

One of the most ubiquitous ideas in the cognitive-aging literature is that as we grow older, our abilities to engage in various forms of cognitive processing decline. Although this is true about a number of aspects of thought, there are some remarkable domains in which cognition remains largely unchanged or may even improve with age. The aim of this article is to present a review of the work that has been done in one of these areas of stability and improvement. This area is the comprehension and memory for situation-specific information, also known as the situation model level of processing (Johnson-Laird, 1983; van Dijk \& Kintsch, 1983; Zwaan \& Radvansky, 1998).

It is well known that there are a number of areas of cognitive decline. For example, there is a decline in the speed with which older adults process information (Hartley, 2006; Salthouse, 1994) that has broad consequences for the effectiveness and efficiency of cognition. For example, it has been suggested that slower processing makes it difficult for older readers to maintain information from prior sections of text that are needed to adequately interpret later sections, such as pronoun anaphors. There is also a general decline in working memory capacity, leaving older adults at a disadvantage in their ability to manage large amounts of information (Craik, Morris, \& Glick, 1989; Salthouse, 1991; Zacks, Hasher, \& Li, 2000). This decline in working memory capacity may reflect a more general decline in the ability to suppress prepotent but irrelevant processing (e.g., Hasher \& Zacks, 1988). Finally, it has been suggested that older adults have difficulty with tasks that require self-initiated processing (Einstein, McDaniel, Richardson, \& Guynn, 1995; Farrimond, Knight, \& Titov, 2006).
Despite these general declines, there are also areas of preservation (Schacter, Kihlstrom, Kaszniak, \& Valdiserri, 1993), including maintained abilities in crystallized intelligence, gist-based processing, and the spread of semantic activation. This review extends these domains to situation model processing, which highlights an area of information processing other than preexperimental knowledge. There have now been a number of studies looking at the influence of aging on situation model creation (Morrow, Stine-Morrow, Leirer, Andrassy, \& Kahn, 1997; Radvansky, Copeland, \& Dijkstra, 2003; Radvansky, Copeland, Berish, \& Zwaan, 2003b; Stine-Morrow, Gagne, Morrow, \& DeWall, 2004; Stine-Morrow, Morrow, \& Leno, 2002), leading to the conclusion that although older adults show marked declines at other levels of processing, such as surface form and textbased levels, efficacy of processing at the situation model level is relatively well preserved (Radvansky, 1999).

Following an overview of situation model theory, two areas of work addressing issues of cognitive aging and situation model use are considered in this review. These are comprehension and memory. After a review of these areas, we will address issues of how working memory span is involved in situation models, how various theories and phenomena of cognitive aging can account for the observed pattern of data, and how these findings on situation model processing fit into a larger theoretical framework of human cognition.

\section{SITUATION MODELS}

To be able to read and comprehend a narrative, a mental model of the text must be constructed that includes the

G.A. Radvansky, gradvans@nd.edu 
characters, their goals and actions, and their relationships to one another, as well as the physical environment they operate in over a certain time period (Trabasso, Suh, Payton, \& Jain, 1995). Readers also make inferences on the basis of their world knowledge and earlier experiences regarding the causes and consequences of events and relationships between events (Rapp \& Gerrig, 2002; Zwaan \& Singer, 2003).

Kintsch and van Dijk (1978) have proposed a theory of text comprehension that includes two levels at which coherence can be achieved by readers and that are essential for understanding a text. Local coherence is established when consecutive propositions can be connected successfully, whereas global coherence occurs when this is accomplished at the text level. Inferences can help to bridge gaps in local or global coherence. Their later model focuses on different levels of representation in text comprehension: the surface form, the textbase, and the situation model (van Dijk \& Kintsch, 1983). This distinction in different levels of representation has been influential in the development of theories and applications of text comprehension and situation model research.

The surface form is a representation of the specific words and syntax used in a text. Although this sort of information is important for initial comprehension processes, it is often rapidly forgotten (Sachs, 1967). The textbase is a representation of the propositional content of the text - that is, the idea units that are actually present in the text. Finally, the situation model (Johnson-Laird, 1983; van Dijk \& Kintsch, 1983; Zwaan \& Radvansky, 1998 ) is a representation, not of the text itself, but of the events described by the text. Thus, the situation model is a more referential mental representation that refers to a set of circumstances in a real or possible world, rather than being directly tied to the specific structure of a text. A situation model serves as an incomplete mental simulation of those described events.

Situation models are composed of a number of components for different aspects of a situation (Wyer \& Radvansky, 1999). First, each situation model is enclosed in a spatial-temporal framework that defines the boundaries of a given event. The spatial framework is the location that the event is unfolding in. Events occurring within that location are considered to be part of the same situation, but events that occur in different locations are treated as different situations (e.g., Radvansky \& Zacks, 1991). Any spatial location that contains an event would serve as a spatial framework, such as a room, building, or other well defined area (e.g., a park). The time frame is the span of time that the event is in force. For example, the duration of a movie would correspond to a time frame, with events that occur during the movie as part of one event. Events that occur beyond that time frame, however, are part of another event (Anderson, Garrod, \& Sanford, 1983).

Within each spatial-temporal framework are a set of tokens that stand for the entities that are involved in the situation. These entities can be people, animals, objects, ideas, and so forth. Comprehenders are influenced by how these entities operate and relate to one another in the situation (Zwaan, 1999). For example, comprehenders can more easily determine whether or not two objects are in the same room when these objects are part of a current description of a room than when they are not (Morrow, Greenspan, \& Bower, 1987), because both the objects and the room are represented in the current situation model. Physical characteristics, such as the color of an object or the attractiveness of a person described in a text, along with how this person feels or what he or she tries to accomplish at a given time, are properties associated with the entities and, therefore, also part of the situation.

Furthermore, within each spatial-temporal framework, there may be a number of structural relations conveying the relationships among the entities in the situation. These structural relations include spatial relations, such as a painting hanging above a desk, social relations between persons in a situation, ownership relations, such as one person buying a car from another person, or kinship relations.

Finally, because situations are dynamic, a series of spatial-temporal frameworks can be joined by linking relations. These linking relations capture temporal and causal relations that produce dynamic changes in a situation. For example, a person may obtain ownership of a car on Monday but may have to sell it on Tuesday after he is fired from his job. These linking relations and changes therein are typically the focus of the ongoing situations because they capture the progression of events and ensuing creation and updating processes of the situation model.

People create a new situation model whenever they encounter a new event or are presented with information that is interpreted as describing multiple locations. An example is when individuals are instructed to memorize multiple sentences. If those sentences can be interpreted as describing a common situation, they can be integrated into a single situation model. However, if they are interpreted as describing multiple situations, a separate situation model is created for each one. For example, a description of a person looking at a clock and stirring a pot can be interpreted as describing the same situation and, so, can be integrated into a common situation model. However, a description of a person making a snowball and a description of that person stirring a pot are likely to be treated as describing separate situations. As a result, people are likely to create a separate situation model to represent each of these circumstances (e.g., Radvansky \& Zacks, 1991; Radvansky, Zwaan, Federico, \& Franklin, 1998).

The other important aspect of situation model processing to be covered is the updating of a situation model of dynamic events. Essentially, as the situation is changing, people need to alter their understanding of what the current state of affairs is. The various types of updating that can occur in situation models will be discussed later when dynamic comprehension is covered.

In the next sections, we will briefly describe some major findings in situation model research on performance in language comprehension and memory. This will be accompanied by a report of how the findings in situation model research that includes elderly populations have not revealed the sorts of age-related declines that would be expected given the difficulties older adults are known to have with other types of processing. 


\section{COMPREHENSION}

Successful comprehension is tantamount to the ability to create a reasonably accurate situation model (van Dijk $\&$ Kintsch, 1983). Having a mental representation of the words, their lexical content, the structure of a sentence, and connections between sentences to establish coherence does not mean that a person has understood a text, any more than a word-processing program understands what is written using it. A higher level of referential representation and understanding is needed. This is the role of the situation model.

Given that situation model construction is so important for successful comprehension (Johnson-Laird, 1983; van Dijk \& Kintsch, 1983; Zwaan \& Radvansky, 1998), the idea that older adults are able to do this should be reflected in their ability to engage in the appropriate cognitive processes during comprehension that lead to an adequate situation model's being created. There are a number of processes that are involved in such situation model construction. These processes include the creation of the situation model and the subsequent updating of that model.

\section{Model Creation}

Situation models are created when readers form a mental representation while reading a text, with each model representing a unique situation or event (Radvansky \& Zacks, 1997). These situation models can represent either dynamic or static situations. A state of affairs is a static situation in which no spatial or temporal change or change in ownership occurs, such as a person's looking at his watch, whereas a course of events is a dynamic situation in which events are linked in a series, such as a person's going from room to room in a house to find a lost book (Barwise \& Perry, 1983).

Two types of relations are relevant in the construction of dynamic or static situations: causality and functional relations (a causal interaction among two or more entities). We first will focus on research in which materials have been used that describe static states of affairs. After that, work involving dynamic situations will be discussed. The first description will cover the comprehension of the causal and temporal aspects of a changing situation, which will be followed by coverage of the processes involved in updating a situation model.

Creation of static situation models at the sentence level. The creation of situation models has been described mostly in relation to narratives that have usually been between 8 and 16 sentences long to allow for elaborate situation model construction (Radvansky \& Curiel, 1998; Zwaan, 1996; Zwaan \& van Oostendorp, 1993). Similar situation model processes occur when sentences are read. Readers make mental representations of described situations or events so long as the description contains sufficient information and detail to construct a mental representation. The ensuing situation models can be considered static because, although a mental representation of the sentence is created, it does not change within the context of the sentence. Thus, we begin our assessment of older adults' situation model processing at this relatively constrained level of input.
Radvansky, Gerard, Zacks, and Hasher (1990) had younger and older participants read sentences that potentially described the same situation, such as The hostess bought a mink coat in the furrier's versus The hostess bought a mink coat from the furrier. The idea was that people would confuse sentences such as these because they likely referred to the same situation. This was in contrast to conditions in which people received sentences that were similarly altered but were unlikely to be interpreted as referring to the same situation, such as The hostess received a telegram in the furrier's versus The hostess received a telegram from the furrier. If people were simply using a linguistic-based memory system, performance in these two conditions would be similar. However, both age groups made more errors in a recognition task when the distractor sentence described a situation similar to that described by the original sentence (young $=.38$; old $=.40$ ) than when the distractor sentence described a different situation (young $=.18$; old $=.25$ ), suggesting similar situation model creation in both age groups (effect size $=1.53$ for young and 1.11 for older adults). ${ }^{1}$ Older adults did make more errors overall, however.

The study described above demonstrates that situation model construction can occur for relatively small discourse units, such as sentences. The finding that more errors are made by younger and older adults when similar situations are described in different sentences suggests that the process of situation model construction is subtle and occurs in a similar manner in younger and older adults. Comparable results have been found at the text level.

Creation of a static situation model at the text level. When a person reads a text, the information that is being read varies in the degree to which it is important for properly understanding the described situation. Some of this information is of only peripheral importance and is likely to play little to no role in the understanding of an event. In contrast, other information is centrally critical to understanding the structure of the ongoing event. An important component to uncovering what is and is not likely to be important in a narrative is the causal structure. Information that has a greater number of causal links, in the sense of being either a cause or an effect of other events in the narrative, is generally more important in the described situation.

The processing of causal information does not appear to be affected by aging. For example, in a study by StineMorrow et al. (2004), younger and older participants were presented with expository and narrative texts that were coded for causal importance. Importance ratings tend to be highly related to the degree of causal connectivity of a text (e.g., van den Broek, 1988). In this study, coding was conducted by a separate group of undergraduates that read passages of the narrative and expository texts and rated each sector of the passage for its importance to the passage as a whole. Reading time data were then submitted to regression analyses that took into account these differences in causal importance, along with other, general characteristics of the texts, such as word frequency and syllable length. What was found was that although older adults did not focus on processing the surface form and textbase levels to the same degree as the younger adults, they were 
more attentive to the situation model level aspects, such as causal importance, relative to the younger adults. Younger adults' reading focused on the situation model level to the degree of that of older adults only during a second reading of the texts, not during the first round.

Another way that the influence of causal relations has been examined is in terms of the processing of functional or nonfunctional spatial relations. Essentially, a functional spatial relation is one in which two entities in the situation either are actively interacting or are in a position to interact. In contrast, a nonfunctional spatial relation is one in which two entities are in some relative spatial relation to one another and are unlikely to be interacting. A hammer above a nail is a functional interaction because the hammer is likely to strike the nail, whereas a hammer to the right of a nail is a nonfunctional relation because there is likely to be no interaction in this case.

A study by Radvansky, Copeland, and Zwaan (2003) examined these sorts of functional relations and how their processing was affected by aging. What was found was that reading times for functional and nonfunctional sentences differed, with people reading functional sentences more quickly than nonfunctional sentences, suggesting that it is easier to integrate that information into the causal structure of the situation model, as compared with nonfunctional information. Importantly, both younger and older adults showed this functionality effect, with younger adults having a 24-msec/syllable reading time difference between these two conditions (the effect size was .51), and the older adults having a $45-\mathrm{msec} /$ syllable reading time difference (the effect size was .60). Clearly, there is no evidence that there is an age-related loss of sensitivity to this sort of processing.

In a conceptually related study by Morrow, Leirer, and Altieri (1992), younger and older adults read a series of passages in which there were protagonists as well as minor characters. What was observed was that although there was an age difference in the ability to resolve anaphors that referred to minor characters, there was no such age effect for the protagonist. Take, for example, the following: The owner told the manager to check the register and liquor cabinets. She turned the front doorknob and made sure it was unlocked. There was an age difference for resolving the anaphor for the minor character she (the manager), but not for the protagonist (in this case, Jill, the waitress).

Thus, components of the situation model that are more prominent and, perhaps, a more integral part of the causal chain, as protagonists are more likely to be, are less affected by aging. Older adults were less accurate in narrative recall, however (which can be generally viewed as a measure of textbase processing), and readers with higher scores on sentence span measures read target sentences more quickly overall and demonstrated better narrative recall. It seems that age effects on updating processes in the situation model were mediated by sentence span.

\section{Creation of Dynamic Situation Models in Texts: Updating}

As has been described earlier, one of the tasks given to readers of a narrative text is to update their understanding of the current situation. These updating changes can take different forms. There are three basic types of updating that we will define here to help with the exposition of the findings in the literature. First, a new element could be introduced into the situation. An example of this would be if a new person walked into the room that a story protagonist was occupying. In this case, the updating process would modify the situation model to include this new information with an additional token to represent the new person. Second, an old element could become irrelevant and would need to be removed from the situation model. An example of this would be if a person walked out of a room. In this case, the updating process would modify the situation model to remove newly irrelevant information from the foreground. Finally, a third type of updating is when there is a change in the quality of some element of the situation, such as a change of ownership of an object or a change of emotion from a neutral state to a sad state - for example, when an accident occurs to a person in the situation (e.g., de Vega, León, \& Díaz, 1996). Because there is no relevant aging research on this last type of updating, we will not discuss it further.

In other words, as things change, people can update their models by adding new elements, removing newly irrelevant elements, or altering the characteristics of existing elements. In terms of the first type of updating, the encounter of a new situational element causes a person to engage in a construction process that involves the establishment of a new situation. Radvansky, Copeland, et al. (2003) examined the updating of situation models as a result of temporal shifts. In this study, people read passages that contained temporal shift sentences that involved either a short time shift (a moment later) or a shift over a longer period of time (a day later). A short time shift involved essentially the same situation, such as painting a wall, whereas a long time shift indicated a major change in the situation, requiring more substantial updating of the situation, such as painting the whole house. What was found was that people were slower to read a sentence with a longer temporal shift than one with a shorter shift. That is, the introduction of a new situational element - in this case, a new time frame - was accompanied by an increase in reading times, which presumably reflected the additional cognitive effort required to update the situation model. Importantly, although the older adults read more slowly, this effect was present for both the younger and the older adults. Specifically, the reading time difference between the short and the long time shift sentences was $236 \mathrm{msec}$ for the younger adults (the effect size was .54) and $449 \mathrm{msec}$ for the older adults (the effect size was .58).

In terms of the second type of updating, the removal of irrelevant information, there have been several studies that assessed updating for different types of situation elements, including space, time, and goals. This sort of updating along the spatial dimension would occur when a person changes location by moving from one place to another, rendering the earlier location irrelevant for the updated situation model.

A study by Radvansky, Copeland, et al. (2003) was modeled after a study by Glenberg, Meyer, and Lindem 
(1987). This study assessed the issue of aging and spatial updating by having people read short texts in which the character moved from one location to another. Of critical importance, prior to the spatial shift, an object was either associated with or dissociated from the person. This object should continue to be in the foreground of the situation model if it was associated with the person prior to moving to a new location. However, it should be removed from the foreground if it was dissociated from the person prior to the shift. What was found was that both younger and older adults showed a spatial shift effect in the accuracy with which questions about the critical object were answered, although older adults were less accurate overall. Moreover, the size of the updating effect was similar in both age groups, with $3.4 \%$ accuracy difference between the associated and the dissociated conditions for the younger adults (the effect size was .55) and a $4.6 \%$ difference for the older adults (the effect size was .43).

In another set of studies of spatial updating by Morrow, Leirer, Altieri, and Fitzsimmons (1994), Morrow et al. (1997), and Stine-Morrow et al. (2002), younger and older adults memorized a map of a building and then read narratives describing a protagonist moving through the building, doing various activities. During reading, people were interrupted with probes about objects in the building. What was observed was that both younger and older adults showed greater availability of object information for the room the protagonist was currently in, relative to objects in other rooms of the building. Moreover, spatial updating seemed to be more difficult for both younger and older readers when the target sentence did not mention the room that contained the target object than when the target sentence did mention the room with the target object (Morrow et al., 1997). Older adults also answered comprehension questions as accurately as younger readers. This suggests that younger adults and older adults updated their situation models to a similar degree.

Removal updating along the temporal dimension occurs when there has been a large shift in time and elements that were relevant in the previous time period are no longer relevant. This issue was examined in more detail in the study by Radvansky, Copeland, et al. (2003) discussed earlier that involved temporal updating. Apart from the reading time data described earlier, after the time shift had been read, people were given a probe word that referred to the active situation prior to the time shift but that would not be relevant after a long time shift. For example, in a story about a novelist, the text referred to the person's writing prior to the time shift, and the probe word was typing. This concept should continue to be foregrounded if there was a short time shift. However, in the case of a long shift in time (e.g., a day later), it would not make sense if a person were still typing; hence, removal updating of what happened the day before would be likely to occur unless a plot-driven explanation could be conceived that would make this continuous typing more plausible - for example, if the reader knew that the novelist would always write books in a stretch of a couple of days (Rapp \& Gerrig, 2002). Radvansky, Copeland, et al. found that both younger and older adults showed a temporal shift effect in the accuracy and response times to these critical probes, although older adults were slower and less accurate overall. The size of the updating effect was similar in both age groups, with $0.5 \%$ accuracy and $95-\mathrm{msec}$ response time differences between the short and the long time shift conditions for the younger adults (the effect size was .05 and .21, respectively) and $2.0 \%$ accuracy and $82-\mathrm{msec}$ response time difference for the older adults (the effect size was .18 and .15 , respectively).

Another example of removing a situation model component when it becomes irrelevant is the removal of goals after they have been completed. A study by Radvansky and Curiel (1998) examined younger and older adults, using a methodology developed by Suh and Trabasso (1993) and Lutz and Radvansky (1997). In this paradigm, people read texts in which a character goal was introduced (e.g., Jimmy wanted to get a bike). Then, later in the story, that goal was either completed (e.g., Jimmy got a bike) or was not and was a failed goal (e.g., Jimmy didn't have the money for a new bike) or a neutral outcome (e.g., it is mentioned that Jimmy had gotten a bike in the past). Availability of the goal was assessed by looking at response times to probe questions that asked about the critical goal. The findings indicated that, for both younger and older adults, the availability of the completed goal, relative to the failed goal, decreased, as demonstrated in longer response times for the completed goal condition. For younger adults, the average difference between the completed and the failed goal conditions was $183 \mathrm{msec}$ (effect size for Experiment $1=.40$, effect size for Experiment $2=.27$ ); it was $227 \mathrm{msec}$ for older adults (effect size for Experiment $1=$ .16 , effect size for Experiment $2=.30$ ). Thus, there is no age deficit in the removal of newly irrelevant goals from the foreground of the situation model.

On the basis of the studies discussed above, we can conclude that situations described in texts are complex. As such, the processing of situation models should reflect this complexity. In most of the research on situation models, the concentration has been on only a single dimension or, perhaps, a pair of dimensions (Zwaan \& Radvansky, 1998). Research has shown, however, that it is possible to disentangle the processing of multiple dimensions in the context of a single study, thereby allowing researchers to use more naturalistic and fewer contrived texts.

One way of doing this is by comparing reading times as a function of whether there is a situational shift along one or more dimensions, such as those outlined by the event indexing model (Zwaan, Langston, \& Graesser, 1995; Zwaan, Magliano, \& Graesser, 1995), along with other text factors that are known to affect processing, such as number of syllables or word frequency. The event indexing model is a theory of how readers monitor multidimensional situations. As readers process and comprehend different aspects of these situations in the text, such as temporality, spatiality, entity, causality, and intentionality, these aspects are constantly monitored and updated to take any spatial, temporal, or causal changes into account (Zwaan, Langston, \& Graesser, 1995). The idea is that people index changes in the dynamic situation by tracking each of these indices of different situations. This is important because it has been 
found that when significant changes occur along any of these index dimensions and the situation model must be appropriately updated, there is also an increase in reading time (e.g., Zwaan, Magliano, \& Graesser, 1995; Zwaan, Radvansky, Hilliard, \& Curiel, 1998).

A study by Radvansky, Zwaan, Curiel, and Copeland (2001) demonstrated how younger and older adults showed reading time slowdowns when situational shifts, such as shifts in time, occurred. Moreover, the sizes of the reading time effects were comparable in the younger and the older adults (see also Stine-Morrow, Loveless, \& Soederberg, 1996, and Miller \& Stine-Morrow, 1998, for a similar outcome using serial position as a measure of situation model processing). That is, when the narratives described shifts in space or time, there was a new agent or goal introduced in the stories, or there was a break in the causal structure, people slowed down when reading these passages. The idea is that at these points, people need to update their situation model to accommodate the various changes. What is interesting about this particular study is that it was able to show that people monitor these various changes simultaneously as they move through a longer, more involved text and that younger and older adults are similarly sensitive to these sorts of event-based changes.

In summary, across a wide range of comprehension tasks, anywhere from simple sentences to longer texts, a number of different processes are thought to operate at the situation model level. These include the understanding of situations described in a single sentence and the detection of temporal and spatial shifts, as well as the tracking of entity information across those shifts, the updating of character goal information, and the general disruption of reading that happens when a situational shift is marked in a text. In all of these cases, when younger and older adults were compared, although older adults may have had worse performance overall, in terms of processing speed or overall accuracy levels, there were no major differences as a consequence of age per se in terms of the measures indicating situation model level processing.

\section{MEMORY}

The three levels of representation necessary for text comprehension (surface form, textbase, and situation model) can be extended to memory as well (van Dijk \& Kintsch, 1983). How does aging affect how well situation models are remembered, relative to the other levels? According to situation model theory, a situation model is a representation of a state of affairs apart from the language used to describe it. As such, it is expected that when people use their situation models to make decisions on the basis of their memory for the text they processed, they will confuse two descriptions that differ in their wording and propositional content but, at the same time, refer to the same event. Furthermore, if younger and older adults maintain their situation models in memory to a similar degree, we can expect them to make these sorts of situationbased errors to a similar extent. This is supported by the Radvansky et al. (1990) study described earlier, in which younger and older adults showed a similar rate of memory confusions for sentences that potentially described the same situation.

We know from several studies of aging that older adults do not remember individual words or sentences, especially syntactically complex sentences, as well as do younger adults (e.g., Engelkamp \& Zimmer, 1997; Stine \& Wingfield, 1990; Stine-Morrow, Ryan, \& Leonard, 2000; Zurif, Swinney, Prather, Wingfield, \& Brownell, 1995). These findings correspond to memory for the surface form and propositional textbase levels that have been found to be compromised in older age. Younger and older adults in Stine and Wingfield's study listened to and recalled expository passages that varied in propositional density and prose length. Older adults recalled a smaller proportion of propositions than did younger adults, especially when passages had greater propositional density, but this occurred regardless of length of the passage.

The question is whether these age differences in text recall also hold for memory at the level of the situation model. A simple way to address this issue is to use a paradigm developed by Schmalhofer and Glavanov (1986). In this paradigm, people are given a text to read. Then, after the text has been read, people are given a recognition test in which they are presented with sentences and asked to indicate whether each of those sentences has been read before in the story. Four classes of recognition probes are presented at test: the original sentence and three distractors (paraphrase, changed meaning with preserved situational correctness, and changed meaning with incorrect situational correctness). After the recognition task, signal detection discrimination scores are obtained to derive measures of the strength of the surface form, propositional textbase, and situation model levels.

There have been a number of experiments using this methodology. The general result is that older adults perform more poorly on the surface form and textbase levels than do the younger adults. However, at the situation model level, older adults do as well as or better than the younger adults (Radvansky, Copeland, et al., 2003; Radvansky, Copeland, \& Zwaan, 2003; Radvansky et al., 2001). This suggests that memory at the situation model level is relatively resilient, as compared with other age-related declines.

Another approach to separating out the effects of the different levels of comprehension on memory was done in a study by Stine-Morrow et al. (1996). As in other work by Stine-Morrow and colleagues, situation model processing was operationalized in terms of serial position, with the idea that people are constructing a situation model as they progress through a text, in line with the structure-building framework (Gernsbacher, 1990). Of particular importance here was the observation that reading strategies differed for younger and older adults. Older adults, who showed better memory for the texts, showed greater sensitivity to processing at the situation model level and less time on surface form and textbase levels than did younger adults. This was in contrast to younger adults with better memory for text, who were more sensitive to the surface form and textbase levels of processing.

According to Stine-Morrow et al. (1996), this asymmetry may reflect differential use of reading strategies based 
on available cognitive resources in different age groups. Younger adults derive their high recall from text-based and bottom-up processing, whereas older adults can reach high levels of recall only when focusing on more global situation model and contextual processing, because the cognitive resources that are used at surface and textbase levels of processing may be insufficient and may not yield optimal recall. In other words, situation-based processing may actually be a strategy used by older readers to compensate for cognitive declines that prevent them from focusing on textbase levels of processing (Stine-Morrow et al., 2002).

The use of situation models in memory can also be assessed in terms of the organization of information in memory. Specifically, people organize information that refers to events in terms of the different situations that are being described. As such, multiple pieces of information that are presented separately but refer to the same situation will be integrated into a common situation model (Bransford \& Franks, 1971). This has consequences for retrieval, in that information referring to similar concepts and information that can be integrated into a common situation model does not produce interference during later retrieval. In contrast, information that refers to similar concepts but does not refer to a common situation is stored in separate situation models in memory. These related models can then compete with one another at retrieval, producing interference (Radvansky \& Zacks, 1991).

What is interesting about this pattern in terms of aging is the degree to which older adults can also successfully integrate information in long-term memory and, thereby, avoid the effects of interference, which can be greater in older adults (Gerard, Zacks, Hasher, \& Radvansky, 1990). Studies by Radvansky, Zacks, and Hasher (1996, 2005) explored this issue and showed that there was no age difference in the ability to integrate information into situation models and avoid fan effect interference. Specifically, both older and younger adults showed interference on a recognition task for information that could readily be integrated into a common situation model. Thus, the use of situation models in memory to avoid associative interference is done in a similar way by younger and older adults.

As with comprehension, there are different components to a situation, and it is reasonable to expect that these components will not all be remembered to the same degree. Specifically, elements that are more important to the situation are remembered better than those that are more peripheral.

One way of looking at memory for central versus peripheral situation information is to compare memory for functional versus nonfunctional information, since functional information would reflect central information, whereas nonfunctional information represents peripheral situation information. In a study by Radvansky, Copeland, and Zwaan (2003; the reading time data during comprehension were described earlier), people read stories that included functional and nonfunctional spatial relations. After reading all of the stories, people were given a forced choice recognition test in which they were to select the spatial relation that they remembered reading in the story.
The results showed that both younger and older adults had better memory for the functional relations than for the nonfunctional ones, with younger adults showing a difference of $23 \%$ in accuracy between these two conditions and older adults showing a difference of $27 \%$ in accuracy. Again, older adults appear to be similar to younger adults in their ability to identify and retain more important aspects of a described situation.

Now that we have considered two main areas of research for situation model processing, comprehension and memory, we will turn to cases in which this age invariance is not observed.

\section{EXCEPTIONS TO AGE INVARIANCE IN SITUATION MODEL PROCESSING}

Note that although there is little to no evidence for age deficits in the creation and updating of situation models during comprehension, this does not mean that other agerelated problems can be safely disregarded as having no impact on situation model level processing. On the contrary, in those cases in which successful model building depends on effective processing at other levels of representation, age differences may be observed.

Some evidence for this comes from a recent study by Copeland and Radvansky (2007), in which people were presented with descriptions of the relations between pairs of objects. This work was based on a study by Ehrlich and Johnson-Laird (1982) that examined the use of textbase and situation model representations when descriptions of spatial relations were comprehended. In this task, people were given three sentence descriptions of the arrangement of four objects. In some cases, the description of each subsequent sentence referred to an object in the previous sentence. This was referred to as the continuous condition. An example of a continuous condition description is the following: (1) The tulip is behind the rose. (2) The rose is to the left of the lily. (3) The lily is in front of the daisy. In comparison, in some cases, the description of the objects in the second sentence did not refer to any of the objects in the first sentence. It was only when people received the third sentence that they could integrate this information into a single coherent situation model. This was referred to as the discontinuous condition. An example of a discontinuous condition is the following: (1) The tulip is behind the rose. (2) The lily is in front of the daisy. (3) The rose is to the left of the lily. The participant's task, after receiving the three descriptions, was to select a diagram that corresponded to the correct arrangement of the four objects.

What Copeland and Radvansky (2007) found was that when these descriptions were sentences or object names in spatial relations, older adults showed a marked decline in performance. That is, they had difficulty holding propositional descriptions in short-term memory and then integrating them into a complete situation model at the end. In fact, older adults were at chance in those conditions in which they needed to hold onto the propositional information before creating an integrated situation model. Thus, deficits at the propositional level produced deficits at the situation model level when model construction de- 
pended on the retention of that propositional information. However, when pictures of objects were presented, the results for the older adults resembled those for the younger adults. The idea is that situation models can be more directly created from nonlinguistic, situational information, removing the need to use propositional codes.

Overall, this pattern of data supports the idea that older adults have problems with situation models when there are difficulties processing at lower levels of comprehension, such as the propositional textbase level. Younger adults, on the other hand, tend to retain textbase information to a greater extent than do older adults (Stine-Morrow et al., 2002). However, when the information being learned and processed more closely matches the structure of a situation model, older adults are able to update their situation models in a manner similar to that for the younger adults.

Generally, older adults have difficulty modifying their understanding of a situation once a mental representation has been created. This is most clearly seen in work by Hamm and Hasher (1992). In that study, people read a set of narratives. For some of these narratives, the readers were initially led to believe that one set of circumstances was true. For example, the readers may have been led to believe that the large building a person was entering was a hospital. Later in the story, information was presented that suggested a different interpretation and, hence, a different situation model, such as learning that the large building was a library. The results showed that although older adults were able to generate a new, correct inference, they also continued to maintain the older, inappropriate inference. Thus, older adults have a decreased ability to regulate the source of the contents of their event understanding, even when faced with clearly contradictory information.

Individual differences in how resources are allocated (e.g., Stine-Morrow, Miller, \& Hertzog, 2006) in conjunction with age also seem to play a role in situation model construction. A study on spatial updating of objects in a building by younger and older adults demonstrated that older adults who were better comprehenders differentially allocated more time to process sentences that did not mention target object locations than did poorer older comprehenders (Morrow et al., 1997). Moreover, regardless of age, better comprehenders slowed down in reading when updating of object location was most difficult. Similar findings were obtained in a spatial updating study in which younger and older readers processed information regarding objects that were located at various distances from the protagonist (Stine-Morrow et al., 2002). Again, older adults who were better comprehenders allocated more processing time to parts in the text that required more substantial updating.

The findings suggest that to compensate for declines in cognitive resources, older adults adapt resource allocation strategies that enable them to create and update situation models successfully. When substantial updating of the situation model is required, as when the distance between the object described in a text and the protagonist is relatively large, this strategy of resource allocation may be more pronounced among good comprehenders and/or older good comprehenders.

\section{SITUATION MODELS AND WORKING MEMORY}

A factor that is relevant to situation model processing that has not been considered so far is the degree to which working memory resources influence the effectiveness of situation model processing. As an area of cognition that is known to decline with aging, working memory capacity may manifest itself in older adults as a performance decrement when dealing with situation models.

There are several aspects of working memory that could be relevant to situation model processing. Perhaps the most extensively studied aspect of working memory has been working memory capacity. Working memory capacity is essentially the amount of active information a person can effectively manage and coordinate at one time. Although there are a number of theories on measures of working memory capacity, this basic idea is common to all of them. This construct is relevant to situation model processing in that the more capacity a person has, presumably, the more effective people are at managing the contents of their situation models, especially as those models become complex.

Although the connection between working memory capacity and situation model processing seems intuitive, recent work on this issue has suggested that there is no clear direct relation. Radvansky and Copeland (2004) found that measures of working memory capacity were unrelated to the ability to remember event descriptions, the detection of situational inconsistencies, and the influence of causal connectivity on performance. In a similar vein, Radvansky and Copeland (2001) found no relation between working memory capacity and situation model updating following spatial shifts. Finally, Radvansky and Copeland (2006) demonstrated that measures of working memory capacity were unrelated to the ability to integrate information into situation models. To our knowledge, attempts to find direct relations between situation model construction and updating with memory span measures have failed so far.

Measures of working memory capacity do appear to be related to verbatim and textbase processing (Radvansky $\&$ Copeland, 2004). That is, working memory span scores appear to reflect the ability to remember specific wordings and the information explicitly contained in a text, rather than the situation described by the text. This is not surprising, given that is exactly what people are asked to do when taking working memory span tests, such as reading and operation span tasks.

Although there is no evidence of a direct relation between working memory capacity, as measured by working memory capacity tests, and situation model processing, we do acknowledge that there can be profound indirect effects. For example, people with limited working memory capacities may have difficulty with long and syntactically convoluted sentences. This would strain their working memory capacity, and as a result, an incomplete or erroneous situation model could be created.

For example, a reader with limited working memory capacity could misinterpret the sentence Harry won a ten- 
nis match against William on a bright sunny day with a cool breeze coming from the North even though he had not been feeling well that morning as William being the one who did not feel well, instead of Harry. In this case, the reader was unable to retain the first part of the sentence referring to Harry in working memory to resolve the anaphor for he. Alternatively, a detail in the situation model could be left out, such as the fact that the breeze came from the North. Nevertheless, this same reader would still correctly construct a situation model of two male tennis players who had their match on a bright sunny day with a cool breeze and one of the players not feeling well. In other words, even if a person's limited working memory capacity results in an incomplete creation of a situation model or a situation model that contains an erroneous detail, construction of this situation model still takes place.

Several studies have revealed the differential allocation of processing resources to adequately update situation models for older adults, relative to younger adults (Morrow et al., 1997; Stine-Morrow et al., 1996). This may be an indication of another indirect relation between working memory capacity and situation model processing (StineMorrow, Milinder, Pullara, \& Herman, 2001). Although older adults seem to construct representations of ideas in the text in a manner similar to that of younger adults, the processing of these ideas takes longer and is affected more by increases in processing load (Stine \& Hindman, 1994; Stine \& Wingfield, 1990). Older adults also allocate less time to process new concepts while reading narratives, especially at the end of sentences (Stine, Cheung, \& Henderson, 1995). Moreover, older adults have more difficulty identifying details in the text that are less important than other details, as compared with younger adults, when the propositional density of the text is greater (Wingfield \& Stine-Morrow, 2000). Therefore, it seems that the difficulties older adults have with processing at the level of the textbase are associated with reduced working memory capacity, since there appears to be interference of less relevant details with more relevant details in the processing of texts with high propositional density.

Another indirect relation between working memory capacity and situation model processing is observed in reasoning. Age-related decrements in performance increase with increases in the number of situation models that are created in evaluation and construction tasks, such as syllogistic reasoning tasks (Gilinsky \& Judd, 1994). Moreover, both working memory and verbal ability (vocabulary) are predictors of age-related reasoning performance (Gilinsky \& Judd, 1994). It seems that agerelated declines in syllogistic reasoning, which can be thought of as involving the evaluation of mental models that people create of the premises (Johnson-Laird, 1983), are mediated by age-related tendencies to accept believable but invalid arguments as valid, whereas unbelievable yet valid arguments tend to be rejected with increasing age (Gilinsky \& Judd, 1994). It is possible that creating situation models of both valid and plausible arguments is too taxing on working memory capacity, resulting in performance decrements.
When working memory capacity is used to divide participants into low-span and high-span readers, it again shows only an indirect relationship with the ability to create and update situation models (Radvansky et al., 1990). Low-span older adults make more errors on sentence comprehension tasks than do high-span older adults, and the difference between low-span and high-span younger adults is smaller (Radvansky et al., 1990). Moreover, when the effective construction of a situation model requires that a person hold a set of verbatim or propositional items in working memory prior to situation model construction, as in Copeland and Radvansky's (2007) integration study described earlier, a deficit at the propositional textbase level puts the older adults at a disadvantage for creating a situation model, because that necessary information is not retained.

If there were a direct relationship between working memory capacity and situation model processing, the general decline in working memory that accompanies aging should result in a decline in performance if situation model processing were heavily dependent on it. That is, older adults are well known as having smaller working memory capacities than do younger adults. If the coordination of the large amounts of information needed to create and update a situation model were dependent on a person's working memory capacity, as measured by traditional measures of working memory span, older adults should have significantly poorer performance at the situation model level. However, no such relationship has been observed.

The findings, described above, indicate an indirect relationship between working memory capacity and situation model processing that supports some of the assumptions of the separate language interpretation resource theory (Caplan \& Waters, 1999; DeDe, Caplan, Kemtes, \& Waters, 2004; Waters, Caplan, \& Rochon, 1995). This theory considers working memory-in particular, the verbal component of working memory - as a separate specialized domain that does not draw on a single resource. According to this account, working memory supports online language comprehension but does not affect offline comprehension processes, such as text recall. This would explain how situation model construction and updating processes could be similar in younger and older adults, as long as these updating processes do not oppose one another, as was the case in the study by Hamm and Hasher (1992).

Our review would not support the single-resource account of cognitive capacity and text comprehension, which claims that there are various processes in comprehension that draw on a common limited cognitive capacity (Carpenter, Miyake, \& Just, 1994; Just \& Carpenter, 1992; Just, Carpenter, \& Keller, 1996). If the assumptions of this theory were applied to situation model construction and aging, the prediction could be made that older adults should be less successful in situation model processing, relative to younger adults, because older adults experience declines in cognitive resources that draw from the same resources as verbatim and textbase processing. As 
less total capacity is available to draw from, comprehension would be negatively affected.

\section{IMPLICATIONS FOR THEORY}

The findings that have been discussed in this article have a number of implications for theory and research in cognitive psychology. The aim of this section is to explore these various implications. First, it will show that this area of research is in line with a broader context of age-invariant cognition, both to suggest how other stable aspects of human cognition may contribute to the preservation of situation model processing and to point out what is unique about this form of preserved processing. Following this exposition, we will discuss the implications for research in language comprehension, working memory, and cognitive aging.

\section{Age-Invariant Cognition}

A central claim of this review is that processing at the situation model level is relatively age invariant, provided that there are no difficulties at other levels of cognition that may provide input to the construction of the situation models. The studies discussed above demonstrated that younger and older adults tend to integrate information into the causal structure of the situation model (Radvansky, Copeland, \& Zwaan, 2003). They also represent prominent and integral components of the situation model in a similar manner (Morrow et al., 1992). Likewise, younger and older adults display similar temporal updating when there is a substantial time shift in the narrative (Radvansky, Copeland, et al., 2003) and spatial updating that involves changes in the availability of an object relative to the protagonist (Morrow et al., 1997; Radvansky, Copeland, et al., 2003; Stine-Morrow et al., 2002). Finally, goal information that has become irrelevant for the situation model is processed in much the same way by younger and older adults.

The extent to which difficulties at other levels of cognition may affect construction and updating of situation models is a topic to which we will return later. At this time, we will address the issue that similarities in situation model processing among younger and older adults are not unique. Rather, there are other aspects of cognition that are relatively well preserved, such as verbal abilities, implicit memory, and crystallized intelligence (Cerella, Rybash, Hoyer, \& Commons, 1993; Schacter et al., 1993). In this section, we will review some of these areas of preserved abilities in aging, to help provide a larger context for understanding preserved situation model abilities. Specifically, we will describe the areas of crystallized intelligence, gist-based memory, and semantic activation.

One area known to be preserved with aging is crystallized intelligence (Horn \& McArdle, 1992), as opposed to fluid intelligence, which shows age-related declines. Crystallized intelligence includes largely semantic knowledge that has accumulated over a lifetime, such as vocabulary and general world knowledge. Fluid intelligence refers to the ability to actively manipulate information. Crystallized intelligence refers to a wide range of semantic memories that are known to be relatively age invariant, including categories, schemas, and scripts (Arbuckle, Vanderleck, Harsany, \& Lapidus, 1990; Hess, 1985).

Preserved schema knowledge in memory for text in old age was demonstrated by Arbuckle and colleagues (1990). Having access to relevant schema information, such as the presence of a title for a text, or having expertise in the subject area described was found to facilitate younger and older adults' ability to remember information from text in cued recall and recognition, as well as free recall measures. Only in the free recall condition did younger adults outperform older adults. Morrow, Leirer, Andrassy, Heir, and Menard (1998) demonstrated a reduction in age differences in the comprehension of medication information when schema-consistent list format and category headers were used. Facilitation of schematically organized materials was also found to facilitate recall in younger and older adults, relative to taxonomically organized materials (Hess, Flannagan, \& Tate, 1993). These findings suggest relative age invariance in schematic processing as a relatively preserved component of the memory system.

Preserved schema knowledge feeds into the understanding of individual events described in texts and, so, is important to situation model processing. When schema-related information is available, such as a title or domain-relevant knowledge, integration of schema-consistent information from the text is facilitated and helps integration of information in the situation model as well. Thus, the better one's schemas are, the better the situation models will be, since they are built based on information from these schemas. Moreover, if older adults have preserved semantic memory, they will continue to be able to utilize this information reliably in the construction of their situation models.

Another way that preserved schema knowledge can facilitate situation model construction is by allocating effort early in the reading process to construct a mental model of the text. This early, schema-based construction may moderate demands on readers' cognitive resources, because situation model creation and updating processes will take place within the constraints of schema-relevant information. It is also likely to preclude text-based levels of processing, because of a stronger emphasis on the gist of the text than on the text itself (Stine-Morrow et al., 1996).

On the basis of the research discussed above, it appears that the range of knowledge that is available to people as they are actively processing information online is essentially the same in younger and older adults. This is important for situation model construction, since an important aspect of this process is the drawing of inferences not explicitly provided. To compensate for lower verbatim or textbase recall, older adults could rely more on existing schematic knowledge and expend more effort during the phase of conceptual organization and integration, in order to construct an elaborate and accurate situation model. For example, older adults who acquired relevant knowledge about a topic were more likely to make elaborative inferences during recall, relative to younger readers, although for both age groups utilization of this knowledge improved comprehension and recall (Miller, Stine-Morrow, Kirkorian, \& Conroy, 2004). Alternatively, increased schema usage could reflect greater expertise on the part of older 
adults who have had more practice at reading than have the younger adults and might not be just a means of compensating for other cognitive declines.

Related to this issue are findings that there is little age difference in gist-based processing (Adams, Smith, Nyquist, \& Perlmutter, 1997; Meyer \& Rice, 1981; Zelinski, Light, \& Gilewski, 1984). Although older adults show marked declines in processing for details from a text, their ability to remember the gist or main point of what they have been presented seems relatively intact (Holland \& Rabbitt, 1990; Zelinski et al., 1984). Preserved memory for gist was also demonstrated in older adults when they were listening to expository discourse under conditions of noise. Younger and older adults demonstrated equal performance on gist recall under these conditions, whereas older adults remembered fewer details overall (Schneider, Daneman, Murphy, \& See, 2000).

A last age-invariant aspect of cognition that is relevant to situation model processing is the spread of activation during semantic retrieval. For example, semantic priming effects are similar in younger and older adults (Balota \& Duchek, 1988; Burke, White, \& Diaz, 1987; Howard, McAndrews, \& Lasaga, 1981; see Duchek \& Balota, 1993, for an overview), with shorter response latencies for high-strength targets in young and older adults, relative to low-strength and neutral targets (Balota \& Duchek, 1988). Similar age invariance has been demonstrated for mediated priming (Bennett \& McEvoy, 1999). The priming effects are even larger for the older adults in raw scores as a result of a relationship between semantic priming and cognitive slowing (Giffard, Desgranges, Kerrouche, Piolino, \& Eustache, 2003; Laver \& Burke, 1993). Thus, the availability of broad-based world knowledge is similar in younger and older adults.

Overall, research on schema knowledge, gist-based text processing, and semantic priming suggests a relative absence of age differences. To some extent, older readers may be compensating for declines in fluid intelligence with preserved crystallized abilities and may use schema-based knowledge to make appropriate inferences and construct elaborate situation models similar to those of younger adults, who can also rely on verbatim and textbase knowledge. Also, it may be that with the substantially greater amounts of practice that older adults have gained over the years, they have become more expert comprehenders and use their schematic knowledge more effectively. Overall, this pattern of findings is consistent with current research on aging issues, both in cross-sectional and longitudinal research, providing evidence concerning preserved abilities in older age and individual differences within older age groups (Andrews, Clark, \& Luszcz, 2002; Newson \& Kemps, 2005).

At this point, it is clear that although older adults have difficulties at lower levels of processing, such as with verbatim and abstract propositional levels, they do not show any clear deficits in the processing of information at the situation model level per se. Most of the deficits that are seen at the situation model level, such as the difficulty older adults had in integrating spatial descriptions in the study by Copeland and Radvansky (2007), can be traced to problems at the surface or textbase levels of processing.
That is, if older adults have difficulty parsing and processing language as it is being heard or read, any subsequent cognitive processes that follow from this, including the construction of a situation model, will suffer.

One question remains after our discussion of research findings that have demonstrated age-related declines at the surface and textbase level in language processing, but not at the level of the situation models: Why is this the case? This question can be broken up into separate questions dealing with different areas of research, such as why working memory span scores do not appear to be directly related to processing at the situation model level, what is different about situation model processing relative to surface and text-based processing, and, finally, why these age differences occur so selectively. Our discussion of implications for different areas of cognition - language processing, the role of working memory in complex thought, and changes in cognitive processing as a result of the natural aging process - will include tentative answers to these questions.

\section{Language Processing}

Because so much of the work on situation model processing is done within the domain of language comprehension, it is not surprising that this age-related finding will have implications for that field. The critical point of the aging work is that although there are declines at the verbatim and propositional levels, there are not marked declines at the situation model level.

Traditional situation model research with younger adults by Kintsch, Welsch, Schmalhofer, and Zimny (1990) showed clear forgetting curves over time at the surface form and textbase levels, but not at the situation model level. Instead, information at the situation model level was retained at a relatively stable level of availability. This suggests that situation models hold a privileged place in cognition and memory that allows them to remain available for much longer periods of time. The results of the work on aging indicate that this privileged status insulates situation model processing from the declines that normally accompany aging as well. The question is, why does this occur?

One possibility for the resiliency of situation models is that they are a more primitive form of cognition. Taking an evolutionary perspective, it seems plausible that other creatures that lack our overblown brain power would have the capability to comprehend the situations that they find themselves in (Magliano, Radvansky, \& Copeland, 2007). This is supported by a good deal of research in the animal learning domain, which shows that the sensitivity to situational structure, including causal structure (in the form of classical conditioning and the like), is well established.

Another explanation for differences between situation model processing and surface and textbase processing is a fundamental difference in function of processing that is the level of involvement or immersion by the reader. The finding that information described in the current situation is more active for the comprehender than information that is not part of the current situation (Glenberg et al., 1987; Morrow et al., 1987) suggests a greater involvement of 
the reader with the current, updated situation than with earlier described situations or situations that are otherwise not current. Spatiotemporal characteristics of the situation may help establish a relatively rich mental representation of the situation in which the comprehender can be immersed. It seems that whereas surface form and textbase processing are important for initial comprehension, elaborate mental representations of situations allow the reader to simulate an experience of the situation similar to what the protagonist would experience.

One reason that older adults are as proficient as younger adults in creating and updating these multilevel situation models could be that older adults utilize previous reading experiences and schema-based knowledge that they accumulated from earlier experiences to build those situation models. These previous reading experiences and their accumulated schema-based knowledge that may be relevant in situation model construction then can help reduce demands on cognitive resources. Instead, these resources may be used to construct elaborate mental representations of the current situation.

Studies have demonstrated that schema utilization reduced age differences in memory for prose passages (Arbuckle et al., 1990), whereas background knowledge contributed to the frequency with which knowledge-based inferences were made by older readers (Miller et al., 2004). In other words, knowledge derived from schemas, other domains, or a lifetime of reading experiences may contribute to a greater efficiency with which processing resources are expended during the construction of mental representations of text and may help older adults to maintain levels of situation model processing similar to those of younger adults (Stine-Morrow et al., 2006).

Regardless of the specific cause(s) for the absence of an age difference, it is clear that the work with older adults reinforces the idea that language processing at the situation model level has characteristics that distinguish it from other levels of processing. Although the processing of situation model representations during comprehension does interact with more language-based processes, to fully understand how situation models are important for language processing, we need to acknowledge that these representations have qualities and properties that are quite different from those derived from linguistic-oriented processes and representations.

\section{Working Memory}

Another domain of cognitive theory for which these findings have serious implications is working memory. Essentially, it is well established that there are declines in working memory capacity as a person ages (Craik \& Byrd, 1982). We have already discussed how working memory limitations will affect situation model processing. Here, we will discuss some ways in which working memory theories are limited in capturing aspects of language processing more generally. However, although such declines do exist, we do not observe any general decline in how situation models are used. In other words, the question is why working memory span scores do not appear to be directly related to processing at the situation model level.
The reason this is an open question is because it is in contrast to a great deal of work showing that working memory span scores are correlated with performance on a number of verbal ability and reading comprehension tests (DeDe et al., 2004; Doiseau \& Isingrini, 2005; Kemper \& Sumner, 2001). However, closer examination of this line of research reveals that much of what is classified as verbal ability and reading comprehension either involve an exclusive focus on the surface form or textbase levels or limit situation model level processing to only a portion of the overall score, along with a heavy influence of surface form and textbase processing (such as the verbal SAT). Thus, although measures of working memory capacity do assess processes that can spill over into deep comprehension, they do not appear to live up to the claim of being a direct indicator of this sort of comprehension.

The age-related findings we have reviewed here are consistent with those in other work, done exclusively with younger adults, that has shown that traditional working memory span scores are unrelated to performance at the situation model level (e.g., Radvansky \& Copeland, 2004). For example, the ability of people to update a situation model is one task that could reasonably be assumed to involve working memory. That is, updating requires a person to actively maintain several pieces of information in order to adjust the structure of their model to accommodate altered circumstances. However, research has shown that the ability to update a situation model is unrelated to these traditional memory span scores (Radvansky \& Copeland, 2001). This does not mean that working memory is not involved in situation model processing. Instead, the work on situation models and aging suggests that the cognitive abilities tapped by traditional memory span measures are not the ones used in situation model processing. It seems likely that there would be involvement of other cognitive resources that are not tapped by these assessments.

\section{Aging}

Finally, our discussion of research findings has implications for theories of cognitive aging. Most theories of cognitive aging have focused on declines in functioning and how they manifest themselves in various ways (Salthouse, 1991; Zacks et al., 2000). There are relatively fewer theories that focus on preserved abilities that exist in the context of these regular declines. The work on situation models and aging is one domain in which preserved cognitive abilities are clearly observed. The question is why this is the case.

Our discussion of the literature suggests that the declines that occur as a result of age-related changes in neurophysiology are largely confined to more delicate cognitive processes, such as those that involve episodic memory for propositions. More fundamental cognitive processes that are likely involved in situation model processing are more likely to be preserved. A parallel to this would be the various cognitive processes that are affected by brain damage, such as amnesia. Episodic memory is more delicate and more prone to disruption, as with retrograde amnesia, which can occur with a blow to the head, than are semantic and procedural memories, which are more durable and 
have better neurological underpinnings (e.g., Tulving, 1985).

It should be noted that more fundamental does not mean less important, nor does it mean that lower level processes are not involved. Situation models are clearly higher level representations. The successful creation of an adequate situation model is tantamount to effective comprehension and can even be thought of as the goal of the comprehension process. Thus, in some sense, the abilities needed to satisfy the basic goal of comprehension remain intact in the face of other age-related declines. The existence of evidence, in some cases, that older adults may actually be more effective at processing at the situation model level suggests that not all age-related changes are negative.

One of the questions that need to be answered is what the impetus is for those cases in which there are actually improvements in processing at the situation model level for older adults. One possibility is that as people age, there are clear declines in some abilities. As such, the person must find some way to compensate for this loss. The situation model level may be one locus of such compensatory efforts. Essentially, as processing abilities at the surface form and textbase levels decline, older adults are forced to place a greater emphasis on schema-based knowledge and the situation model level to counteract this deficit. Thus, older adults may be better able to abstract the moral of a story but, at the same time, have poorer memory for the story itself (Adams, 1991; Adams et al., 1997; Narvaez, Radvansky, \& Lynchard, 2007). They also seem to utilize background knowledge to make elaborative inferences during recall of a text and respond better to inference-based comprehension questions, relative to younger adults (Miller et al., 2004). In other words, if older adults can tap into a knowledge base of a longer reading history and focus on applying this knowledge and conceptual integration while processing a text, this may pay off in the construction and updating of situation models that turn out to be similar to those of younger adults and possibly contain a larger inference structure than do those of younger adults.

Work in other areas of cognitive gerontology, such as schema processing, has suggested that older adults are more likely to rely on gist-based representations, as opposed to more detailed representations (Holland \& Rabbitt, 1990). This makes older adults more prone to false memories and schema-consistent inferences, because they may incorporate erroneous yet gist-consistent information into their situation model of the events described. The work on situation models may be seen as being in line with this general characteristic of aging. And, to some degree, it is. However, the preserved processing at the situation model level goes beyond gist-based representations by using schemas, as well as including functional relations between entities that are part of the events described.

Although a situation model can be viewed as less detail oriented than is a surface form or textbase representation, it is not simply the case that older adults are engaged in more gist-based and general processing. Situation model processing is more elaborate than general information pro- cessing and using schemas. Many of the preserved processing abilities that older adults have at the situation model level must take into account the specific, detailed aspects of the ongoing situation. For example, the processing of functional relations requires an understanding of how two entities are interacting in a meaningful way, which may not be schema based (such as standing under a bridge to get out of the rain). Also, preserved or superior memory at the situation model level on recognition tests using the Schmalhofer and Glavanov (1986) procedure requires discriminating between inferences and incorrect statements, both of which are thematically consistent with the text. If older adults were simply engaging in gist-based processing, it would be expected that they would have a harder time discriminating between these two and should do worse than the younger adults. However, the opposite is true.

\section{CONCLUSIONS}

Over the past several years, there has been a great deal of work addressing the issue of whether older adults show deficits in processing at the situation model level. The general consensus appears to be that there is no decline. This occurs in the face of other cognitive declines, such as a slowdown in processing speed (Salthouse, 1996), smaller working memory capacities (Craik \& Byrd, 1982), declines in inhibitory abilities (Hasher \& Zacks, 1988), and decreased abilities to initiate cognitive processes (Craik, 1977), such as those found with prospective memory. This review has illustrated the expansiveness of this preserved cognitive ability and has explored how it is related to other abilities that are preserved in cognitive aging.

This work has implications for research in language comprehension, working memory, and aging in showing that the situation model is a more fundamental level of understanding that is relatively durable in the face of deficits at other, more abstract levels of processing. Given the cognitive declines that unmistakably exist in older adults, the preservation of mental processing and representation at the level of the situation model suggests that this is a more robust form of thought that is more firmly established and can withstand the various declines that accompany aging. It seems unlikely that this age-related stability is solely a consequence of an increase in gist-based processing. Instead, this durability may arise from the use of more fundamental representational processes that would be less likely to suffer under the relatively mild neurological disruption that accompanies normal aging. This has the broader implication that situation model processing, although a "higher level" process, is a more rudimentary form of thought than is the processing of propositional information that is found in so much of the research on memory and comprehension.

\section{AUTHOR NOTE}

We thank Elizabeth Stine-Morrow and two anonymous reviewers for their insightful comments. Please address all correspondence regarding this article to G. A. Radvansky, Department of Psychology, University of Notre Dame, Notre Dame, IN 46556 (e-mail: gradvans@nd.edu). 


\section{REFERENCES}

ADAms, C. (1991). Qualitative age differences in memory for text: A lifespan developmental perspective. Psychology \& Aging, 6, 323-336.

Adams, C., Smith, M. C., Nyquist, L., \& Perlmutter, M. (1997). Adult age-group differences in recall for the literal and interpretive meanings of narrative text. Journals of Gerontology, 52B, P187P195.

Anderson, A., Garrod, S. C., \& SAnford, A. J. (1983). The accessibility of pronominal antecedents as a function of episode shifts in narrative texts. Quarterly Journal of Experimental Psychology, 35A, 427-440.

Andrews, G., Clark, M., \& Luszcz, M. (2002). Successful aging in the Australian Longitudinal Study of Aging: Applying the MacArthur model cross-nationally. Journal of Social Issues, 58, 749-765.

Arbuckle, T. Y., Vanderleck, V. F., Harsany, M., \& Lapidus, S. (1990). Adult age differences in relation to availability and accessibility of knowledge-based schemas. Journal of Experimental Psychology: Learning, Memory, \& Cognition, 16, 305-315.

Balota, D. A., \& DucheK, J. M. (1988). Age-related differences in lexical access, spreading activation, and simple pronunciation. Psychology \& Aging, 3, 84-93.

Barwise, J., \& Perry, J. (1983). Situations and attitudes. Cambridge, MA: MIT Press.

BennetT, D. J., \& McEvoy, C. L. (1999). Mediated priming in younger and older adults. Experimental Aging Research, 25, 141-159.

Bransford, J. D., \& Franks, J. J. (1971). The abstraction of linguistic ideas. Cognitive Psychology, 2, 331-350.

Burke, D. M., White, H., \& Diaz, D. L. (1987). Semantic priming in young and older adults: Evidence for age constancy in automatic and attentional processes. Journal of Experimental Psychology: Human Perception \& Performance, 13, 79-88.

Caplan, D., \& Waters, G. S. (1999). Issues regarding general and domain-specific resources. Behavioral \& Brain Sciences, 2, 77-94.

Carpenter, P. A., Miyake, A., \& Just, M. A. (1994). Working memory constraints in comprehension: Evidence from individual differences, aphasia, and aging. In M. A. Gernsbacher (Ed.), Handbook of psycholinguistics (pp. 1075-1122). San Diego: Academic Press.

Cerella, J., Rybash, J., Hoyer, W., \& Commons, M. L. (1993). Adult information processing: Limits on loss. San Diego: Academic Press.

CoHen, J. (1988). Statistical power analysis for the behavioral sciences (2nd ed.). Hillsdale, NJ: Erlbaum.

Copeland, D. E., \& Radvansky, G. A. (2007). Aging and integrating spatial mental models. Psychology \& Aging, 22, 569-579.

CraIK, F. I. M. (1977). Age differences in human memory. In J. E. Birren \& K. W. Schaie (Eds.), Handbook of the psychology of aging (pp. 384420). New York: Van Nostrand Reinhold.

Craik, F. I. M., \& Byrd, M. (1982). Aging and cognitive deficits: The role of attentional resources. In F. I. M. Craik \& S. Trehub (Eds.), Aging and cognitive processes (pp. 191-211). New York: Plenum.

Craik, F. I. M., Morris, R. G., \& Glick, M. L. (1989). Adult age differences in working memory. In G. Vallar \& T. Shallice (Eds.), Neuropsychological impairments of short-term memory (pp. 247-267). Cambridge: Cambridge University Press.

DeDe, G., Caplan, D., Kemtes, K., \& Waters, G. (2004). The relationship between age, verbal working memory, and language comprehension. Psychology \& Aging, 19, 601-616.

De Vega, M., León, I., \& Díaz, J. M. (1996). The representation of changing emotions in reading comprehension. Cognition \& Emotion, 10, 303-321.

DoISEAU, F., \& IsINGRINI, M. (2005). Updating information in verbal working memory and executive functioning. Psychological Reports, 96, 67-76.

DucheK, J. M., \& Balota, D. A. (1993). Sparing activation processes in older adults. In J. Cerella, J. Rybash, W. Hoyer, \& M. L. Commons (Eds.), Adult information processing: Limits on loss (pp. 383-406). San Diego: Academic Press.

EhrLich, K., \& Johnson-LaIRD, P. N. (1982). Spatial descriptions and referential continuity. Journal of Verbal Learning \& Verbal Behavior, 21, 296-306.

Einstein, G. O., McDaniel, M. A., Richardson, S. L., \& Guynn, M. J. (1995). Aging and prospective memory: Examining the influ- ences of self-initiated retrieval processes. Journal of Experimental Psychology: Learning, Memory, \& Cognition, 21, 996-1007.

ENGELKAMP, J., \& ZiMMER, H. D. (1997). Sensory factors in memory for subject-performed tasks. Acta Psychologica, 96, 43-60.

FARrimond, S., KNIGHT, R. G., \& Titov, N. (2006). The effects of aging on remembering intentions: Performance on a simulated shopping task. Applied Cognitive Psychology, 20, 533-555.

Gerard, L., Zacks, R. T., Hasher, L., \& Radvansky, G. A. (1990). Age deficits in retrieval: The fan effect. Journals of Gerontology, 46B, P131-P136.

GernsBaCher, M. A. (1990). Language comprehension as structure building. Hillsdale, NJ: Erlbaum.

Giffard, B., Desgranges, B., Kerrouche, N., Piolino, P., \& EuSTACHE, F. (2003). The hyperpriming phenomenon in normal aging: A consequence of cognitive slowing? Neuropsychology, 17, 594-601.

GilinsKY, A. S., \& JUDD, B. B. (1994). Working memory and bias in reasoning across the life span. Psychology \& Aging, 9, 356-371.

Glenberg, A. M., Meyer, M., \& Lindem, K. (1987). Mental models contribute to foregrounding during text comprehension. Journal of Memory \& Language, 26, 69-83.

Hamm, V. P., \& Hasher, L. (1992). Age and the availability of inferences. Psychology \& Aging, 7, 56-64.

Hartley, A. (2006). Changing role of the speed of processing construct in the cognitive psychology of human aging. In J. E. Birren \& W. K. Schaie (Eds.), Handbook of the psychology of aging (6th ed., pp. 183207). Amsterdam: Elsevier.

HASHER, L., \& ZACKS, R. T. (1988). Working memory, comprehension, and aging: A review and a new view. In G. Bower (Ed.), The psychology of learning and motivation: Advances in research and theory (Vol. 22, pp. 193-225). San Diego: Academic Press.

HEss, T. M. (1985). Aging and context influences on recognition memory for typical and atypical script actions. Developmental Psychology, 21, 1139-1151.

Hess, T. M., Flannagan, D. A., \& Tate, C. S. (1993). Aging and memory for schematically vs. taxonomically organized verbal materials. Journals of Gerontology, 48B, P37-P44.

Holland, C. A., \& RabBITT, P. M. A. (1990). Autobiographical and text recall in the elderly: An investigation of a processing resource deficit. Quarterly Journal of Experimental Psychology, 42A, 441-470.

Horn, J. L., \& McArdLE, J. J. (1992). A practical and theoretical guide to measurement invariance in aging research. Experimental Aging Research, 18, 117-144.

Howard, D. V., McAndrews, M. P., \& Lasaga, M. I. (1981). Semantic priming of lexical decisions in young and old adults. Journals of Gerontology, 36B, P707-P714.

JoHnson-LaIRD, P. N. (1983). Mental models: Towards a cognitive science of language, inference, and consciousness. Cambridge, MA: Harvard University Press.

Just, M. A., \& CARPENTER, P. A. (1992). A capacity theory of comprehension: Individual differences in working memory. Psychological Review, 99, 122-149.

Just, M. A., Carpenter, P. A., \& Keller, T. A. (1996). The capacity theory of comprehension: New frontiers of evidence and arguments. Psychological Review, 103, 773-780.

Kemper, S., \& Sumner, A. (2001). The structure of verbal abilities in young and older adults. Psychology \& Aging, 16, 312-323.

KinTsCH, W., \& VAN DIJK, T. A. (1978). Toward a model of text comprehension and production. Psychological Review, 85, 363-394.

Kintsch, W., Welsch, D., Schmalhofer, F., \& Zimny, S. (1990). Sentence memory: A theoretical analysis. Journal of Memory \& Language, 29, 133-159.

LaVer, G. D., \& BurKe, D. M. (1993). Why do semantic priming effects increase in old age? A meta-analysis. Psychology \& Aging, 8, 34-43.

LutZ, M. F., \& Radvansky, G. A. (1997). The fate of completed goal information in narrative comprehension. Journal of Memory \& Language, 36, 293-310.

Magliano, J., Radvansky, G. A., \& Copeland, D. E. (2007). Beyond language comprehension: Situation models as a form of autobiographical memory. In F. Schmalhofer \& C. Perfetti (Eds.), Higher level language processes in the brain: Inference and comprehension processes (pp. 379-392). Mahwah, NJ: Erlbaum.

Meyer, B. J. F., \& Rice, G. E. (1981). Information recalled from prose 
by young, middle, and old adult readers. Experimental Aging Research, 7, 253-268.

Miller, L. M. S., \& Stine-Morrow, E. A. L. (1998). Aging and the effects of knowledge on on-line reading strategies. Journals of Gerontology, 53B, P223-P233.

Miller, L. M. S., Stine-Morrow, E. A. L., Kirkorian, H. L., \& ConROY, M. L. (2004). Adult age differences in knowledge-driven reading. Journal of Educational Psychology, 96, 811-821.

Morrow, D. G., Greenspan, S. L., \& Bower, G. H. (1987). Accessibility and situation models in narrative comprehension. Journal of Memory \& Language, 26, 165-187.

Morrow, D. G., Leirer, V. O., \& Altieri, P. A. (1992). Aging, expertise, and narrative processing. Psychology \& Aging, 7, 376-388.

Morrow, D. G., Leirer, V. O., Altieri, P. A., \& Fitzsimmons, C. (1994). Age differences in creating spatial models from narratives. Language \& Cognitive Processes, 9, 203-220.

Morrow, D. G., Leirer, V. O., Andrassy, J. M., Heir, C. M., \& MeNARD, W. E. (1998). The influence of list form and category headings on age differences in understanding medication instructions. Experimental Aging Research, 24, 231-256.

Morrow, D. G., Stine-Morrow, E. A. L., Leirer, V. O., Andrassy, J. M., \& KAHN, J. (1997). The role of reader age and focus of attention in creating situation models from narratives. Journals of Gerontology, 52B, P73-P80.

Narvaez, D. F., Radvansky, G. A., \& Lynchard, N. A. (2007). Aging and spontaneous moral character evaluation. Manuscript submitted for publication.

Newson, R. S., \& Kemps, E. B. (2005). General lifestyle activities as a predictor of current cognition and cognitive change in older adults: A cross-sectional and longitudinal examination. Journals of Gerontology, 60B, P113-P120.

RadVAnsky, G. A. (1999). Aging, memory and comprehension. Current Directions in Psychological Science, 8, 49-53.

Radvansky, G. A., \& Copeland, D. E. (2001). Working memory and situation model updating. Memory \& Cognition, 29, 1073-1080.

Radvansky, G. A., \& Copeland, D. E. (2004). Working memory and situation model processing: Language comprehension and memory. American Journal of Psychology, 117, 191-213.

Radvansky, G. A., \& Copeland, D. E. (2006). Memory retrieval and interference: Working memory issues. Journal of Memory \& Language, 55, 33-46.

Radvansky, G. A., Copeland, D. E., Berish, D. E., \& Dijkstra, K. (2003). Aging and situation model updating. Aging, Neuropsychology, \& Cognition, 10, 158-166.

Radvansky, G. A., Copeland, D. E., \& Zwaan, R. A. (2003). Aging and functional spatial relations in comprehension and memory. Psychology \& Aging, 18, 161-165.

Radvansky, G. A., \& Curiel, J. M. (1998). Narrative comprehension and aging: The fate of completed goal information. Psychology \& Aging, 13, 69-79.

Radvansky, G. A., Gerard, L. D., Zacks, R. T., \& Hasher, L. (1990). Younger and older adults' use of mental models as representations for text materials. Psychology \& Aging, 5, 209-214.

RADVANSKY, G. A., \& ZACKS, R. T. (1991). Mental models and the fan effect. Journal of Experimental Psychology: Learning, Memory, \& Cognition, 17, 940-953.

RADVANSKY, G. A., \& ZACKS, R. T. (1997). The retrieval of situationspecific information. In M. A. Conway (Ed.), Cognitive models of memory (pp. 173-213). Cambridge, MA: MIT Press.

RAdVANSKy, G. A., Zacks, R. T., \& Hasher, L. (1996). Fact retrieval in younger and older adults: The role of mental models. Psychology \& Aging, 11, 258-271.

RADVANSKY, G. A., ZACKs, R. T., \& HASHER, L. (2005). Age and inhibition: The retrieval of situation models. Journals of Gerontology, $60 \mathrm{~B}$, P276-P278.

Radvansky, G. A., Zwaan, R. A., Curiel, J. M., \& Copeland, D. E. (2001). Situation models and aging. Psychology \& Aging, 16, $145-$ 160

Radvansky, G. A., Zwahn, R. A., Federico, T., \& Franklin, N. (1998). Retrieval from temporally organized situation models. Journal of Experimental Psychology: Learning, Memory, \& Cognition, 24, 1224-1237.
RAPP, D. N., \& GERRIG, R. J. (2002). Reader's reality-driven and plotdriven analyses in narrative comprehension. Memory \& Cognition, 30, 779-788.

Rosnow, R. L., \& Rosenthal, R. (1996). Computing contrasts, effect sizes, and counternulls on other people's published data: General procedures for research consumers. Psychological Methods, 1, 331-340.

SACHS, J. S. (1967). Recognition memory for syntactic and semantic aspects of connected discourse. Perception \& Psychophysics, 2, 437 442.

Salthouse, T. A. (1991). Theoretical perspectives on cognitive aging. Hillsdale, NJ: Erlbaum.

Salthouse, T. A. (1994). Aging associations: Influence of speed on adult age differences in associative learning. Journal of Experimental Psychology: Learning, Memory, \& Cognition, 20, 1486-1503.

Salthouse, T. A. (1996). Constraints on theories of cognitive aging. Psychological Review, 3, 287-299.

Schacter, D. L., Kihlstrom, J. F., Kaszniak, A. W., \& Valdiserri, M. (1993). Preserved and impaired memory functions in elderly adults. In J. Cerella, J. Rybash, W. Hoyer, \& M. L. Commons (Eds.), Adult information processing: Limits on loss (pp. 327-350). San Diego: Academic Press.

Schmalhofer, F., \& Glavanov, D. (1986). Three components of understanding a programmer's manual: Verbatim, propositional, and situational representations. Journal of Memory \& Language, 25, 279294.

Schneider, B. A., Daneman, M., Murphy, D. R., \& See, S. K. (2000). Listening to discourse in distracting settings: The effects of aging. Psychology \& Aging, 15, 110-125.

Stine, E. A. L., Cheung, H., \& Henderson, D. (1995). Adult age differences in the on-line processing of new concepts in discourse. Aging \& Cognition, 2, 1-18.

Stine, E. A. L., \& Hindman, J. (1994). Age differences in reading time allocation for propositionally dense sentences. Aging \& Cognition, 1, 2-16.

Stine, E. A. L., \& Wingfield, A. (1990). How much do working memory deficits contribute to age differences in discourse memory? European Journal of Cognitive Psychology, 2, 289-304.

Stine-Morrow, E. A. L., Gagne, D. D., Morrow, D. G., \& DeWall, B. H. (2004). Age differences in rereading. Memory \& Cognition, 32, 696-710.

Stine-Morrow, E. A. L., Loveless, M. K., \& Soederberg, L. M. (1996). Resource allocation in on-line reading by younger and older adults. Psychology \& Aging, 11, 475-486.

Stine-Morrow, E. A. L., Milinder, L., Pullara, O., \& Herman, B. (2001). Patterns of resource allocation are reliable among younger and older readers. Psychology \& Aging, 16, 69-84.

Stine-Morrow, E. A. L., Miller, L. M. S., \& Hertzog, C. (2006). Aging and self-regulated language processing. Psychological Bulletin, 132, 582-606.

Stine-Morrow, E. A. L., Morrow, D. G., \& Leno, R. (2002). Aging and the representation of spatial situations in narrative understanding. Journals of Gerontology, 57B, P291-P297.

Stine-Morrow, E. A. L., Ryan, E. A., \& Leonard, S. (2000). Age differences in on-line syntactic processing. Experimental Aging Research, 26, 315-322.

Suh, S., \& Trabasso, T. (1993). Inferences during reading: Converging evidence from discourse analysis, talk-aloud protocols, and recognition priming. Journal of Memory \& Language, 32, 279-300.

Trabasso, T., Suh, S., Payton, P., \& Jain, R. (1995). Explanatory inferences and other strategies during comprehension and their effect on recall. In R. F. Lorch, Jr. \& E. J. O'Brien (Eds.), Sources of coherence in reading (pp. 219-239). Hillsdale, NJ: Erlbaum.

Tulving, E. (1985). How many memory systems are there? American Psychologist, 40, 385-398.

VAN DEN BROEK, P. (1988). The effects of causal relations and hierarchical position on the importance of story statements. Journal of Memory \& Language, 27, 1-22.

VAN DIJK, T. A., \& KINTSCH, W. (1983). Strategies in discourse comprehension. New York: Academic Press.

Waters, G. S., Caplan, D., \& Rochon, E. (1995). Processing capacity and sentence comprehension in patients with Alzheimer's disease. Cognitive Neuropsychology, 12, 1-30. 
Wingfield, A., \& Stine-Morrow, E. A. L. (2000). Language and speech. In F. I. M. Craik \& T. A. Salthouse (Eds.), The handbook of aging and cognition (2nd ed., pp. 359-416). Mahwah, NJ: Erlbaum.

WYER, R. S., JR., \& RADVANSKY, G. A. (1999). The comprehension and validation of social information. Psychological Review, 106, 89-118.

ZACKS, R. T., HASher, L., \& LI, K. Z. H. (2000). Human memory. In F. I. M. Craik \& T. A. Salthouse (Eds.), Handbook of aging and cognition (2nd ed., pp. 293-357). Mahwah, NJ: Erlbaum.

Zelinski, E. M., Light, L. L., \& Gilewski, M. J. (1984). Adult age differences in memory for prose: The question of sensitivity to passage structure. Developmental Psychology, 20, 1181-1192.

Zurif, E., Swinney, D., Prather, P., Wingfield, A., \& Brownell, H. (1995). The allocation of memory resources during sentence comprehension: Evidence from the elderly. Journal of Psycholinguistic Research, 24, 165-182.

ZWAAN, R. A. (1996). Processing narrative time shifts. Journal of Experimental Psychology: Learning, Memory, \& Cognition, 22, 1196-1207.

ZWAAN, R. A. (1999). Situation models: The mental leap into imagined worlds. Current Directions in Psychological Science, 8, 15-18.

ZwaAn, R. A., Langston, M. C., \& Graesser, A. C. (1995). The construction of situation models in narrative comprehension: An eventindexing model. Psychological Science, 6, 292-297.

Zwaan, R. A., Magliano, J. P., \& Graesser, A. C. (1995). Dimensions of situation model construction in narrative comprehension. Journal of Experimental Psychology: Learning, Memory, \& Cognition, 21, 386-397.

ZWAAN, R. A., \& Radvansky, G. A. (1998). Situation models in language comprehension and memory. Psychological Bulletin, 123, 162185.

Zwaan, R. A., Radvansky, G. A., Hilliard, A. E., \& Curiel, J. M. (1998). Constructing multidimensional situation models during reading. Scientific Studies of Reading, 2, 199-220.

ZwaAn, R. A., \& Singer, M. (2003). Text comprehension. In A. C. Graesser, M. A. Gernsbacher, \& S. R. Goldman (Eds.), Handbook of discourse processes (pp. 83-121). Mahwah, NJ: Erlbaum.

ZWAan, R. A., \& VAN OOSTENDORP, H. (1993). Do readers construct spatial representations during naturalistic story comprehension? Discourse Processes, 16, 125-143.

\section{NOTE}

1. Effect sizes were calculated using the formula provided by Cohen (1988) and Rosnow and Rosenthal (1996).

(Manuscript received November 29, 2006; revision accepted for publication March 23, 2007.) 